ELUA

ISSN 2171-6692

Núm. 35, 2021, págs. 93-107

https://doi.org/10.14198/ELUA2021.35.5

\title{
SPANISH VS. ENGLISH DISAGREEMENT: AN ANALYSIS OF CULTURAL AND SITUATIONAL VARIATION
}

\section{DESACUERDO ESPAÑOL E INGLÉS: UN ANÁLISIS DE VARIACIÓN CULTURAL Y SITUACIONAL}

\author{
Francisco Fernández-García \\ University of Jaén, Spain \\ fcofer@ujaen.es \\ https://orcid.org/0000-0002-8102-1617 \\ Carmen María SÁnchez-Morillas \\ University of Jaén, Spain \\ cmsanche@ujaen.es \\ https://orcid.org/0000-0002-6622-212X
}

\begin{abstract}
This paper highlights the results of an intercultural study within the theoretical frame of (im) politeness about the way in which Spanish and English speakers manage situations of disagreement. However, in order not to ignore the internal variation that in each culture exists, cultural contrasts are analysed while simultaneously taking into account situational variation.

This study is based upon a questionnaire carried out among 240 informants. Using open questions, both qualitative and quantitative methodology is employed. As regards (im) politeness, the rapport management theory by
\end{abstract}

\begin{abstract}
Resumen
Este trabajo ofrece los resultados de un estudio intercultural, desde el marco teórico de la (des) cortesía, acerca del modo en que hablantes españoles e ingleses gestionan situaciones de desacuerdo. Además, con el objetivo de no pasar por alto la variación interna existente dentro de cada cultura, el contraste cultural es analizado a la vez que se da cuenta de la variación situacional.

El estudio está basado en un cuestionario distribuido a 240 informantes. Sobre la base de preguntas abiertas, se utiliza metodología tanto cualitativa como cuantitativa. En relación con la
\end{abstract}

To cite this article: Fernández-García, Francisco y Sánchez-Morillas, Carmen María (2021). Spanish vs. English disagreement: An analysis of cultural and situational variation. ELUA, 35: 93-107. https:// doi.org/10.14198/ELUA2021.35.5

Recibido: 24/07/2020, Aceptado: 08/11/2020

(C) 2021 Francisco Fernández-García, Carmen María Sánchez-Morillas

Este trabajo está sujeto a una licencia de Reconocimiento 4.0 Internacional

de Creative Commons (CC BY 4.0) 
Spencer-Oatey $(2002,2008)$ is the model employed for reference.

The replies of the informants are analysed regarding their possible reaction to a situation of disagreement in different contextual frames. It is observed whether the speaker does or does not express disagreement, as well as the way it is expressed (mitigated, open or boosted) and the kind of strategies that are employed.

KEYWORDS: disagreement; (im)politeness; intercultural pragmatics; variational pragmatics; situational variation. (des)cortesía, el modelo teórico de referencia es el de gestión interrelacional (rapport management) de Spencer-Oatey $(2002,2008)$.

Las respuestas de los informantes son analizadas en relación con su posible reacción a una situación de desacuerdo en diferentes contextos situacionales. Se observa si el hablante expresa o no desacuerdo, así como el modo en que este es expresado (mitigado, abierto o potenciado) y el tipo de estrategias empleadas para hacerlo.

PALABRAS CLAVE: desacuerdo; (des)cortesía; pragmática intercultural; pragmática variacionista; variación situacional.

\section{INTRODUCTION}

Studies on politeness have come a long way since the very first pioneering offerings of the seventies and eighties of the previous century (Lakoff, 1973; Brown y Levinson, 1978, 1987; Leech, 1983). Indeed, we now have, no doubt, widespread knowledge acquired about the way in which the management of (im)politeness conditions how communication and - through this - human relationships take place. A widely analysed aspect in this sense include studies about which intercultural differences exist (for example, Wierzbicka, 2003; or Spencer-Oatey, ed., 2008). Such research, however, has often ignored the issue of intracultural pragmatic variation (with exceptions such as that of Schneider, 2012; or Staley, 2018). For this reason, one must believe that any description of communicative behavioural patterns of a culture as a homogeneous whole - in general, and regarding (im)politeness in particular - can inevitably only be partial and reductionist, offering a biased vision of reality. Furthermore, this is due not only to internal social variation but also to the prime relevance of situational variation: the situational frame (Terkourafi, 2005: 247-248; Holmes: 2013: 76) in which communicative interaction takes place is another key conditioning factor regarding an individual's (im)polite behaviour.

For all the above reasons, if aiming to understand in depth the different forms of (im)politeness that one person could adopt, it is necessary to do so using a three-dimensional analysis, taking into consideration the different elements of cultural, social and situational variation. What is more, if cultural behaviour patterns are perceived, these must necessarily be interpreted as having a dynamic nature and should be regarded as the sum of internal varieties. Hence, starting with these premises and focusing specifically on the way in which cultural variation and situational variation interact, the following specific objectives in this study are proposed:

a) to contextualise the research carried out, starting from traditional approaches of intercultural pragmatics and presenting the basic guidelines of the research project of which this study forms a part;

b) to check whether one can distinguish different cultural patterns between Spanish and English speakers regarding how they deal with disagreement in conversation; 
c) to analyse whether such patterns, if they exist, are lineal and stable within each culture or whether, on the contrary, they are subject to significant change depending on situational factors of internal variation. ${ }^{1}$

\section{THEORETICAL-METHODOLOGICAL APPROACH}

Studies about politeness have traditionally distinguished between cultures which tend towards closeness and those which favour distance; or, to use Brown and Levinson's (1978, 1987) classic terminology, cultures which tend towards positive politeness and those which incline preferably towards negative politeness (such a distinction can also be found, among many other works, in Sifianou, 1992; Haverkate, 2003; or Holmes, 2013). Within this traditional frame has been placed the stereotypical opposition between the conversational behaviour of Spanish and English speakers, the former clearly tending towards positive politeness and the latter showing an open preference for the negative type (Briz, 2012: 56). One generally assumes that the Spanish speaker prefers a closeness of solidarity, whereas the English one is more inclined to be respectfully distant. Thus, Lorenzo-Dus (2001: 109) writes about the contrast between the preference of open expression on a Spanish speaker's part when it comes to positive politeness and an English speaker's reticence in this sense. Stewart (2005: 117), on his part, characterises the British culture as "an avoidance based, negatively oriented culture"; and, finally, Ballesteros Martín (2001: 195) talks about the Spaniard's preference for encouraging social relations within a group in contrast to the British person's need for privacy and individuality.

In a similar vein, Bravo (2001: 305-306), regarding the criticism aimed at the presumed universality of Brown and Levinson's model (1978, 1987), highlights that their model places the wish to not impose, which is typically British and linked to negative politeness, as the core concept of politeness, whereas Spanish speakers endeavour to channel their efforts towards achieving affiliation amongst speakers, indeed, towards positive politeness. Hernández Flores $(1999,2003)$ adds that a key trait in Spanish communicative behaviour is the importance of confianza ('rapport'), which is essential for the affiliative face of the cultural group: the possibility of behaving and speaking in an open way, without fear of offending people who one supposedly knows well. The role of rapport for a Spanish speaker is also highlighted in works by Hernández López and Placencia (2004) or Bravo (2008).

Together with these descriptions which characterise the behaviour of Spanish and English speakers in a global way, we find - as explained in the introduction - the need to also investigate the internal variation which exists within each culture. This is indeed the starting point of the present study, which has been carried out using the information obtained through a questionnaire delivered in 2016 to informants in the surroundings of the city of Jaén (Andalusia, Spain) and Coventry (West Midlands, England), in its respective Spanish or English version. 240 informants took part in the study, 120 from each area, selected according to three social variables, namely, sex, age and education.

1 This article presents, for the first time together, the main results of a wide research project. Parts have already been detailed in other publications which are all in Spanish. Its theoretical-methodological approach is explained in Fernández-García (2016a and 2016b) and in Fernández-García and Ortiz-Viso (2018); its empirical analysis of disagreement can be found in Fernández-García and Aguayo-Cruz (2019), in Fernández-García (under evaluation) and in Fernández-García (2020). 
The questionnaire consists of ten questions through which it aims to obtain information about different aspects regarding the speakers' perception and ways of dealing with (im)politeness. Two of such questions, number 3 and 4, specifically concentrate on disagreement and were designed with the concrete aim of paying attention to the impact of situational variation on the communicative behaviour of the informants. These questions are reproduced below in their English version:

3. Consider the following scenario. You are having a lively conversation with a friend (colleague, neighbour, etc.) you trust in a relaxed atmosphere. You are at home or in a restaurant. Talking about a current issue you are very interested in, your friend expresses an opinion you do not agree with at all. How would you react? Try to reproduce here what words you might say.

Now imagine that something similar happens (you do not agree at all with something said by your interlocutor), but at the doctor's surgery, and you do not have a particularly close relationship with the doctor. What would you say?

4. Now imagine that the conversation with your friend (from the previous question) is becoming heated, with a series of disagreements, to the point where it has turned into an argument. Then your friend contradicts you in a particularly critical way that makes you feel very annoyed (for example, telling you that you're saying that because you have no idea what you're talking about). How would you react? Try to reproduce here what words you might say.

Question 3 stresses the relevance that a change of communicative frame could have, considering two alternatives: an informal context of rapport as opposed to a formal context lacking rapport in which one finds an asymmetrical social relationship. Question 4, on its part, acting as a continuation of the first part of question 3, lays emphasis on the role of the transformation of the same communicative frame, analysing the attitude of the speaker when faced with a disappearance of cordiality and the emergence of a hostile atmosphere in an informal context.

Two last issues should be explained before finishing this theoretical-methodological section. Firstly, as regards the questions used in the questionnaire, they were - as can be observed - of an open nature. This fact has made it possible to combine the qualitative analysis with the quantitative one: an initial qualitative analysis, providing a wealth of nuances offered by the informant, and a subsequent quantitative analysis based on the analytical categories obtained in the qualitative analysis. Secondly, the theoretical foundation of this analysis of (im)politeness corresponds to that of the rapport management theory of Spencer-Oatey $(2002,2005,2007,2008)$. In line with this theory, two essential aspects are distinguished regarding an individual's social projection, namely, one's face and sociality rights. In turn, the former comprises one's quality face, social identity face and relational face, and within the latter, equity rights and association rights.

\section{CULTURAL AND SITUATIONAL VARIATION OF DISAGREEMENT}

Disagreement is an assertive speech act which arises as a response to another speech act of the same nature, that is, as the second part of an adjacency pair. According to Levinson (1983: 336), it is a dispreferred second part, characterised by using more linguistic content, 
by being more indirect, etc. Schegloff (2007: 59), in turn, highlights that adjacency pairs constitute sequences aimed at carrying out a particular activity, a process in which the preferred alternative is precisely that which provides this objective, whereas the dispreferred one, in some way, hinders it; one sees, consequently, that agreement is seen as natural, whereas disagreement has a dysfunctional nature. In this sense, we are faced with a conceptualisation which fits perfectly into Brown and Levinson's (1987: 112-117) view that to "seek agreement" and to "avoid disagreement" are respective strategies of positive politeness.

However, this perception of disagreement must be countered by the opinions of those who hold that the (im)polite nature of this speech act reflects a cultural stamp, given the existence of cultures where the dissent of the interlocutor, far from being considered as threatening to his/her face, tends to be considered as a polite, affiliative gesture. This argument is upheld, for example, by Blum-Kulka (1982) or Schiffrin (1984) regarding the Jewish culture, or by Bravo (2003) regarding the Spanish one. For this reason, the tendency in discordant conversations between Spaniards is to reaffirm rather than attenuate, without considering that this attitude implies a risk to the interlocutor's face (Bravo, 2003: 107; Hickey, 2005: 322). Hernández López and Placencia (2004: 137), in turn, explain that even in a non-discordant communicative context where there is a lack of rapport between the speakers, Spaniards appear more assertive, show a greater tendency to disagree and tolerate disagreement more.

Taking all the above into account, this research has analysed three aspects regarding each one of the three questions in the questionnaire presented in $\S 2$ (which henceforth will be referred to as $3 \mathrm{a}, 3 \mathrm{~b}$ and 4 , according to the position in which they appear in the original questionnaire):

a) whether, when faced with the interlocutor's opinion, the informant either expresses or not his/her disagreement, and which other reactions, different of disagreement, take place instead or concurrently $(\S 3.1)$;

b) in the case of informants who show disagreement, in which cases does it appear as formulated in a mitigated, open or boosted way (\$ 3.2$)$;

c) which strategies the speakers employ to formulate to their interlocutor those mitigated forms of disagreement $(\S 3.3)$.

These analyses have proved to be complex and have generated an enormous amount of data which would be impossible to give in complete detail here. Subsequently, only the key principles of these results will be presented.

\subsection{Expression or non-expression of disagreement; other reactions}

As aforementioned, the first step in this analysis has been to study the behaviour of speakers when faced with the quandary of expressing or not expressing disagreement, as well as alternative or complementary reactions to this disagreement that appear (Fernández-García and Aguayo-Cruz, 2019). This has been done, firstly, by using the data in table 1:

\begin{tabular}{|c|c|c|c|}
\cline { 2 - 4 } \multicolumn{1}{c|}{} & Question 3a & Question 3b & Question 4 \\
\hline Jaén & $91.67 \%$ & $55.00 \%$ & $50.00 \%$ \\
\hline Coventry & $73.33 \%$ & $45.83 \%$ & $34.17 \%$ \\
\hline
\end{tabular}

Table 1. Percentage of informants showing disagreement 
The initial idea taken into account — based on the bibliographical sources consulted - is that a Spanish speaker, in general, is more assertive, tending to disagree more than an English speaker. Furthermore, according to the data collected, this is reflected in the relaxed and informal context of question $3 \mathrm{a}$ (the relaxed conversation with a friend), in which the formulation of disagreement on the part of the Spaniards is practically systematic $(91.67 \%$ of all cases). The Spanish speakers, in effect, feel freer to speak without fear of offending their interlocutors compared to the English speakers, who are clearly more reticent in this case (showing disagreement in $73.33 \%$ of all cases), among other reasons, due to fear of spoiling their social relationship with their friend. It is in this informal context, in fact, where one finds the greatest manifestation of cultural difference between the Spaniards and the English, both in their expression of disagreement as well as in their use of other reactions and the nature of these, as we shall see later on.

From this initial idea, however, one observes that although certain differentiated cultural patterns continue to be valid when an informal relaxed frame is transformed into an asymmetrically formal one (passing from question $3 a$ to question $3 b$, indeed, transitioning from a relaxed conversation with a friend to a conversation in a doctor's practice) and when the relaxed informal frame is converted into one of tension (passing from question 3 a to question 4 , that is to say, a relaxed conversation with a friend being transformed into an argument); even though - as aforementioned - this does happen, it is also true that these situational variations go hand in hand with the different and relevant processes of homogenization between the communicative behaviours of speakers of the two cultures, either in the substantially lower number of disagreements in both and the closing of the gap between them in this sense, or in the much greater similarity between them, both in their expression of other reactions (alternative or complementary to disagreement) as well as in the nature of these reactions.

Hence, according to the data found in table 1, the passing from $3 \mathrm{a}$ to $3 \mathrm{~b}$ provokes a drastic decrease in expression of disagreement in both cultures, reducing the distance between them to a minimum (among the Spaniards this goes from $91.67 \%$ to $55.00 \%$ of the informants; among the English, from $73.33 \%$ to $45.83 \%$ ). Therefore, both the sustained cultural difference (the Spaniard's greater tendency to disagree), as well as the enormous impact of the contextual frame (a parallel lessening of disagreement in both cultures) are patent. Moreover, if we were to talk about passing from 3 a to 4 , we again find that expression of disagreement is reduced in both cases, even more than in the context of $3 \mathrm{~b}$ (among the Spaniards, from $91.67 \%$ to $50.00 \%$; among the English, from $73.33 \%$ to $34.17 \%$; which again manifests the pressure exerted by the transformation of the contextual frame).

The change (from $3 a$ to $3 b$ ) or the evolution (from $3 a$ to 4 ) of the contextual frame shows clearly, therefore, that cultural differences are maintained, and that communicative behaviours tend to become homogeneous, responding in a similar way to contextual pressure. Furthermore, as mentioned previously, this not only occurs in the expression of disagreement but also in the expression of other alternative or complementary reactions to disagreement. The qualitative analysis of this study has pinpointed ten of these reactions, among which the following will be referred to in the next paragraphs:

1. Assuming disagreement naturally.

2. Demanding respect for one's opinion; criticising or lamenting the attitude of the interlocutor. 
3. Asking for further explanations.

4. Keeping quiet, ignoring, not paying attention.

5. Putting an end to the conversation or changing the subject. ${ }^{2}$

The global way in which the informants used these other reactions is reflected in table 2:

\begin{tabular}{|c|c|c|c|}
\cline { 2 - 4 } \multicolumn{1}{c|}{} & Question 3a & Question 3b & Question 4 \\
\hline Jaén & $14.17 \%$ & $50.83 \%$ & $70.00 \%$ \\
\hline Coventry & $41.67 \%$ & $50.00 \%$ & $72.50 \%$ \\
\hline
\end{tabular}

Table 2. Percentage of informants showing other alternative or complementary reactions to disagreement

Just as in the expression or non-expression of disagreement, the cultural difference is at its greatest in the relaxed informal context of 3a, in which the Spanish speaker, beyond expressing disagreement in a practically systematic way (table 1), hardly shows any other reaction (only in $14.17 \%$ of all the cases); and when this does occur, he/she does so showing no interest in the interlocutor's opinion (where the reaction of "keeping quiet, ignoring, not paying attention" predominates ${ }^{3}$ ). In contrast to this attitude, we can also see in table 2 that the other reactions of the English speakers are virtually three-fold those of the Spaniards ( $41.67 \%$ of the informants), as well as being openly different from a qualitative perspective: assuming disagreement naturally and asking for further explanations are the main ones used (both, indeed, sustainably characteristic of the English speakers in the different contexts analysed), reactions which could be considered more conciliatory and open to dialogue.

However, as previously said, the change of contextual surroundings, passing from a relaxed informal frame (in 3a) to the asymmetrically formal frame (in 3b), demonstrates its enormous power to homogenise in certain aspects, in order to minimalize cultural difference. Beyond the fact that the expression of other reactions becomes more numerous in both cultures (table 2) due to the decrease of expression of disagreement (table 1), it is interesting to find a specific rise of these reactions among the Spaniards, which is slightly higher than among the English (among the Spaniards it goes from $14.17 \%$ to $50.83 \%$ of all cases, whereas among the English it goes from $41.67 \%$ to $50.00 \%$; table 2). Consequently, the Spanish speaker shows a significant change of attitude in $3 \mathrm{~b}$, clearly convergent with that of the English speaker; indeed, convergent to such an extent that four of the main reactions of both nationalities are the same. Moreover, in some of these, one clearly perceives how different cultural tendencies blend with the homogenisation of communicative behaviours imposed by the context. This occurs with "keeping quiet, ignoring, not paying attention" (which continues to be a principally Spanish reaction, but which becomes more widespread among the English speakers) or with "asking for further explanations" (which the English speakers continue to excel in, but which gains greater presence among the Spaniards).

2 These "other reactions" are not a central issue in this paper; that is the reason why only the five later mentioned are presented here.

3 In order to avoid a proliferation of data, an analysis of percentage weight of each one of these reactions will not be made. 
In a similar way, the evolution from the relaxed informal frame (in $3 a$ ) to the informal frame of tension (in 4) homogenises certain aspects of communicative behaviour relative to the other reactions of the Spaniards and the English. In this sense, according to the data presented in table 2, one can see that the numbers of such reactions rise enormously (running parallel to the drastic decrease in the expression of disagreement; table 1) and that, just as in $3 \mathrm{~b}$, they are used practically equally by both nationalities (in this case $70.00 \%$ of the Spaniards and $72.50 \%$ of the English). What is more, it is interesting to observe that the main reaction of both is the same, and is, curiously, the one which was hardly used either in $3 a$ or $3 b$, namely, "putting an end to the conversation or changing the subject". This is a reaction that in the previous contexts was of unique relevance to the English speakers, and which was practically unused by the Spaniards, and which now, although maintaining a greater use among the English (cultural pattern), also acquires great relevance among the Spaniards (situational pressure). Altogether, this reaction is a protagonist in context 4 and is clearly brought about by the specific characteristics which have impregnated the informal frame on acquiring a stroke of tension.

Before coming to the end of this section it is necessary to pause on some additional issues. Firstly, one must highlight the fact that only $57.44 \%$ of the Spaniards who showed disagreement in the relaxed informal frame of $3 \mathrm{a}$ did so also in the tense informal frame of $4(91.60 \%$ of the informants of the former compared to $50.00 \%$ in the latter; table 1$)$. This makes one question the idea that, among Spaniards, dissenting in a discordant context of rapport constitutes an act of an affiliative nature. Indeed, it has been shown that when faced with this conflictive situation (context 4), many of the informants decide to retract. Added to this is the relevance of the reaction "demanding respect for one's opinion; criticising or lamenting the attitude of the interlocutor" in context 4 among the Spaniards, which makes one think that tolerance towards disagreement in discordant contexts among Spaniards is maybe lower than previously assumed.

However, the impact of rapport for a Spanish speaker, as opposed to an English one, does seem clear, as it is precisely in the contexts of rapport (3a and 4) where the formulation of disagreement reaches its widest gap between the Spaniards and the English, although this gap is almost bridged in the asymmetrical formal frame (3b) (table 1). Hence, regarding the formulation of disagreement, it is plausible to give importance to the line which crosses the cultural with the situational when evaluating the influence that the social relationship between the speaker and the interlocutor has. Indeed, the possibility of putting a friendship at risk (in 3a and in 4) seems more important to the English speaker, whereas the possibility that a disagreement could be interpreted as a lack of respect to the social status of a doctor (in $3 b$ ) seems to influence the Spanish speaker more.

\subsection{Mitigated, open or boosted disagreement}

The second step in this analysis has been to observe, among those informants who decided to show disagreement to their interlocutor's opinion, which ones did so in a mitigated way, which in an open way, and which in a boosted way (Fernández-García, under evaluation). The results of this analysis are presented synthetically, placing them in relation to the basic keys of this study regarding formulation or non-formulation of disagreement as explained in $\S 3.1$. 
Let us begin with the relaxed informal context of $3 a$ (the relaxed conversation with a friend), which can be seen in table 3 .

\begin{tabular}{|c|c|c|c|}
\cline { 2 - 4 } \multicolumn{1}{c|}{} & Mitigated & Open & Boosted \\
\hline Jaén & $68.35 \%$ & $17.72 \%$ & $13.92 \%$ \\
\hline Coventry & $80.33 \%$ & $11.48 \%$ & $8.20 \%$ \\
\hline
\end{tabular}

Table 3. Percentage of informants who show mitigated, open or boosted disagreement in question $3 \mathrm{a}$

These figures show, in coherence with the lower English tendency to disagree (table 1), that these informants appear to use mitigation more when deciding to formulate disagreement (indeed, $80.33 \%$ of the English informants who expressed disagreement did it through mitigation). The Spaniards, however, who tend to express disagreement more (table 1), use mitigation less when doing so $(68.35 \%$ of the Spaniards who expressed disagreement did it through mitigation). Furthermore, the Spaniards outnumber the English in both open disagreement (17.22\% of the Spaniards compared to $11.48 \%$ of the English) and in boosted disagreement (13.92\% of the Spaniards compared to $8.20 \%$ of the English). Hence, it seems clear -in line with the bibliographical predictions - that the Spaniards' role of rapport is relevant as it allows them to express themselves more openly. Nonetheless, one should not forget that, in reality, the quantitative difference between the two is hardly enormous (11.98\% more of the English opt for a mitigated form of disagreement compared to the Spaniards), which could lead us to the conclusion that, notwithstanding differential nuances, the generalised tendency to mitigate (rounding off, eight out of ten English mitigate and seven out of ten Spaniards) indicates that both nationalities consider disagreement as a socially dangerous action.

As regards the asymmetrical formal context of $3 \mathrm{~b}$ (the conversation in a doctor's practice), it is a fact that, although being the Spaniards more prone to disagreement, the gap between their use of it and that of the English is minimal (table 1). Moreover, the change of frame goes hand in hand with a very defined tendency change regarding the way of formulating disagreement. This can be seen in table 4 :

\begin{tabular}{|c|c|c|c|}
\cline { 2 - 4 } \multicolumn{1}{c|}{} & Mitigated & Open & Boosted \\
\hline Jaén & $88.10 \%$ & $7.14 \%$ & $4.76 \%$ \\
\hline Coventry & $67.74 \%$ & $22.58 \%$ & $9.68 \%$ \\
\hline
\end{tabular}

Table 4. Percentage of informants who show mitigated, open or boosted disagreement in question $3 \mathrm{~b}$

It is evident that the Spaniards mitigate more than the English, with an even greater difference than that which we found inversely in $3 \mathrm{a}$ (to a doctor, only $67.74 \%$ of the English informants who expressed disagreement do so in a mitigated way, compared to $88.10 \%$ of the Spaniards); what is more, the English employ open disagreement three times more than the Spaniards (22.58\% compared to 7.14\%) and the former use boosted disagreement two times more than the latter $(9.68 \%$ compared to $4.76 \%)$. In these cases the figure of the interlocutor 
appears to be key: the Spanish speakers feel slightly more at liberty to use mitigation with a friend thanks to the rapport between the two, but feel obliged to do so with a doctor due to the distance and social hierarchy which separates them. The English speakers, on their part, mitigate more when contradicting their friend due to a fear of spoiling the social tie which unites them, but do not feel this pressure when speaking to a doctor. Two major conclusions can be reached here: firstly, that we cannot trust the generalised idea that English speakers use mitigation more and are less assertive than the Spaniards, as the influence of the contextual frame plays a key role; secondly, that the expectation that attenuation decreases amongst the Spaniards the closer, the more cordial and the more informal they become (Briz, 2012: 48) is not applicable to the English, as — at least in the contexts analysed - the proportion who do this is exactly the inverse.

Regarding the tense informal context of 4 (the conversation with a friend, now becoming a heated argument), we begin with the premise that this contextual change produces a more than perceptible reduction of expression of disagreement, which is more marked among the English and less among the Spaniards (table 1); and that it provokes the homogenisation of alternative or complementary reactions of disagreement (table 2). We will now see that such homogenisation is even greater in the ways in which disagreement is formulated, as table 5 reveals:

\begin{tabular}{|c|c|c|c|}
\cline { 2 - 4 } \multicolumn{1}{c|}{} & Mitigated & Open & Boosted \\
\hline Jaén & $11.36 \%$ & $9.09 \%$ & $79.55 \%$ \\
\hline Coventry & $11.54 \%$ & $11.54 \%$ & $76.92 \%$ \\
\hline
\end{tabular}

Table 5. Percentage of informants who show mitigated, open or boosted disagreement in question 4

The figures here are similar for both nationalities: the mitigated disagreements plummet (Spaniards: 11.36\%; English: 11.54\%) and the total sum of open and boosted disagreements shoot up $(88.64 \%$ of the Spaniards and $88.46 \%$ of the English, corresponding to $9.09 \%$ of the open and $79.55 \%$ of the boosted in the Spaniards, and to $11.54 \%$ of the open and $76.92 \%$ of the boosted in the English). Consequently, the enormous power of contextual variation is manifest (in the evolution of 3 a to 4 , that is to say, in the transformation from a relaxed conversation with a friend into an argument), as this contextual variation makes the formulation of disagreement drop drastically (table 1), it makes the proportions between mitigation and boosting become inverted diametrically (tables 3 and 5) and, consequently, the cultural differences between the informants become blurred and practically disappear (table 5).

These results lead us to question the possible impolite character of disagreement. This idea has already been rejected as an apriorism, in accordance with the cultural differences described in this sense $(\S 3)$. However, beginning with the verification that both English and Spaniards drastically reduce their expression of disagreement in the conflictive context of question 4 (table 1), we now see further that they mitigate in quite a generalised way in $3 \mathrm{a}$ and $3 \mathrm{~b}$ (the non-conflictive contexts; tables 3 and 4). These facts make it easy to deduce that disagreement is considered by both as a potentially harmful act regarding the balance of social relations with the interlocutor. This seems to be the cause for its 
configuration as the second dispreferred part — both structurally (Levinson, 1983: 336) and psychologically (Bousfield, 2008: 237) — of the assertive adjacent pairs, as seen in $3 \mathrm{a}$ and $3 \mathrm{~b}$. However, when the conversation becomes tense and heated, and the structural transformation takes place (Kothoff, 1993) turning it into an argument - the case of question 4 - , the preference changes and disagreement becomes the structurally preferred option, even though it is still psychologically dispreferred. It is from this discordance that an openly impolite manner arises (the speaker opts in favour of formulating disagreement in a clear, direct, concise way - structural preference- despite being conscious that the interlocutor prefers — psychological preference — the opposite). Hence, we could conclude that, as far as the contexts under scrutiny are concerned, disagreement appears as a potentially impolite verbal action, whose mitigation is interpreted as a polite effect and whose boosting is interpreted as an impolite effect, and that this occurs, roughly, in a similar way for the informants of both nationalities.

\subsection{Mitigation strategies}

After analysing which informants opted in favour of formulating or not disagreement (or other possible reactions), presented in $\S 3.1$, and which among the former did so in a mitigated, open or boosted way, presented in $\S 3.2$, the third step in this research has been to analyse the strategies employed by the informants who opted for polite mitigation of disagreement (Fernández-García, 2020). We already know that the attitude of the informants of both nationalities was to incline towards the use of strategies of mitigation of disagreement both in question 3a (relaxed informal context; table 3) as well as in $3 b$ (asymmetrical formal context; table 4), whereas this use was drastically reduced in the answers to question 4 (informal tense context; table 5), in which strategies of boosted disagreement were a clear protagonist. This is the reason why, in order to count on data of quantitative relevance, this analysis on the use of strategies of mitigation centres exclusively on the responses to $3 \mathrm{a}$ and $3 \mathrm{~b}$.

The qualitative analysis of the replies to these questions has unveiled the presence of seven different functional strategies, which are presented below according to the social aspect of the individual (Spencer-Oatey, 2002, 2008) to which they are connected: ${ }^{4}$

a) Aimed at the quality face (despite disagreement, the speaker values the interlocutor's opinion):

1) show respect for the opinion of the interlocutor;

2) minimalize disagreement.

b) Aimed at equity rights (the speakers try not to impose themselves on their interlocutor):

3) relativize the weight of their own opinion, diminish assertiveness;

4) encourage reconsideration.

c) Aimed at association rights (the speaker shows respect towards the interlocutor and his/ her social role, offering a certain emotional implication with him/her):

5) lamenting the disagreement or apologising for it;

6) showing that disagreement is inevitable or incompatible with wishes to be frank;

7) showing camaraderie or good humour.

4 As one can observe, concerning face, strategies aimed only at quality face, but not at social identity face or relational face have been detected. In the frame of sociality rights, however, we do find strategies aimed both at equity rights and association rights. 
The quantitative analysis has thrown the following figures regarding the global weight of each one of the three strategic groups:

\begin{tabular}{|c|c|c|c|}
\cline { 2 - 4 } \multicolumn{1}{c|}{} & $\begin{array}{c}\text { Quality } \\
\text { face }\end{array}$ & $\begin{array}{c}\text { Equity } \\
\text { rights }\end{array}$ & Association rights \\
\hline Jaén & $22.35 \%$ & $61.18 \%$ & $14.12 \%$ \\
\hline Coventry & $26.47 \%$ & $47.06 \%$ & $24.99 \%$ \\
\hline
\end{tabular}

Table 6. The use of mitigation strategies, according to the social aspect to which they point, in question $3 \mathrm{a}$

\begin{tabular}{|c|c|c|c|}
\cline { 2 - 4 } \multicolumn{1}{c|}{} & $\begin{array}{c}\text { Quality } \\
\text { face }\end{array}$ & $\begin{array}{c}\text { Equity } \\
\text { rights }\end{array}$ & Association rights \\
\hline Jaén & $23.08 \%$ & $55.77 \%$ & $21.15 \%$ \\
\hline Coventry & $00.00 \%$ & $59.26 \%$ & $37.03 \%$ \\
\hline
\end{tabular}

Table 7. The use of mitigation strategies, according to the social aspect to which they point, in question $3 \mathrm{~b}$

In the study of the data obtained, what stands out first is the generalised predominance in both cultures and in both contextual frames ( $3 a$ and $3 b$ ) of strategies aimed at equity rights - the closest conceptually to the negative face of Brown and Levinson $(1978,1987)$ and connected to the individual's right to not being imposed, fairness of treatment, etc.- : in $3 \mathrm{a}$ this affects $61.18 \%$ of the Spanish cases and $47.06 \%$ of the English (table 6 ); in $3 \mathrm{~b}$ this affects $55.77 \%$ of the former and $59.26 \%$ of the latter (table 7 ). This general predominance contravenes its expected greater presence in English speakers; and is contravened in particular in the relaxed informal context of $3 \mathrm{a}$, in which its use on the parts of the informants of Jaén far surpasses those of Coventry. In fact, strategy 3 ("relativize the weight of their own opinion, diminish assertiveness") is the most used in both contexts by both nationalities, with surprisingly high figures in the case of the Spaniards and noticeably lower in the case of the English. ${ }^{5}$ On the other hand, still regarding strategies connected to equity rights, it is striking that the expected — according to Holmes (1995:19-20), among others - higher number of this type of strategy in formal contexts (the case of $3 b$ ), tending more towards estrangement than in informal contexts (the case of 3a), is found to be true amongst the English informants, but not amongst the Spaniards.

To compensate this, what is no less surprising is the protagonism of the mitigation aimed at the quality face - close, conceptually speaking, to the positive face of Brown and Levinson $(1978,1987)$ and based on the desire of the individual to be valued positively by others - in the attitude of the English speakers in the informal context of 3a (particularly in the case of strategy 2, "minimalizing disagreement"), which even outnumbers the Spaniards $(26.47 \%$ in the former, $22.35 \%$ in the latter; table 6), against all predictions from the bibliography. Additionally, as regards the expected lower use of this type of strategy (those linked to the quality

5 As pointed out in footnote $3(\S 3.1)$, in order to avoid a proliferation of data, here an analysis of percentage weight of each one of these strategies in each culture and each situational frame will not be made. 
face, which are considered to belong more to contexts of rapport) in the asymmetrical formal context of $3 \mathrm{~b}$, we find that this is not true amongst the Spaniards (in fact, percentage-wise, we find the use of these strategies to be slightly higher: $22.35 \%$ in $3 \mathrm{a}$ and $23.08 \%$ in $3 \mathrm{~b}$ ) and amongst the English we find an extreme decrease in its use, from $26.47 \%$ to $0.00 \%$, that is to say, that its use completely disappears (tables 6 and 7). This confirms the qualitative change of communicative behaviour of the latter when passing from a conversation with a friend to a dialogue in a doctor's practice: they use much less mitigation (tables 3 and 4) and centre exclusively on sociality rights — of equity and association- (tables 6 and 7), which, far from the essentially affective appearance of face, revolve around "people's concerns over fairness, consideration and behavioural appropriateness" (Spencer-Oatey, 2008: 13-14).

Finally, as regards association rights, one must remember that these are about the right of individuals to be treated according to the type and grade of social relation which they have with their interlocutors. In the case of the Spaniards, these constituted the strategies least employed in both contexts (altogether 14.12\% in 3a and 21.15\% in 3b; tables 6 and 7); however, they are more relevant in the case of the English, and what is more, this is emphasised in $3 \mathrm{~b}$ due to the complete disappearance of strategies related to face (altogether, $24.99 \%$ in $3 \mathrm{a}$ and $37.03 \%$ in $3 \mathrm{~b}$; tables 6 and 7). As for concrete strategies, the different behaviour of strategy 5 ("lamenting the disagreement or apologising for it") was expected in this case. It is a strategy that shows respect towards the interlocutor and his/her social role: whilst being of secondary importance in the informal context of $3 \mathrm{a}$ for both the Spaniards and the English, its presence is multiplied in both cases once they find themselves in the asymmetrical formal context of 3b. And, finally, let us end with the typically English trait of strategy 6 ("showing that disagreement is inevitable or incompatible with wishes to be frank"), which is characteristic of speakers of this nationality and appears as constant in both contexts.

\section{CONCLUSIONS}

This paper began by insisting on the inappropriateness of approaching intercultural pragmatic analyses through a comparison between monolithic and homogeneous cultural blocks, considering that social variation and situational variation could significantly modulate behavioural patterns within a society. This work, after first positioning the research carried out within the context of classic approaches towards intercultural pragmatics (the first of the objectives indicated in $\S 1$ ), then proceeds to centre this study around the combined analysis of cultural variation and situational variation, and has effectively confirmed that one can ascertain constant cultural tendencies which indicate generally different lines of behaviour between the Spaniards and the English (the second objective). But, at the same time, it is manifest that there are situational conditioning factors which exert a highly significant pressure on the speaker, to the extent that, in marked contexts, they substantially blur the aforementioned cultural differences and to a large extent make the communicative behaviour of the speakers converge (the third objective).

Although it is true that, in line with what is expected, the Spanish speaker is revealed to tend more openly to disagree than the English, it is also true that this behaviour is particularly associated with the unframed context of a colloquial conversation of rapport, whereas the opposing cultural profiles seem to fade away — at least in part - when the communicative frame changes or evolves into other situations framed as formal or conflictive. However, 
by observing which option (mitigated, open or boosted) is chosen by those speakers who decide to express disagreement, we find it untenable to state generally that the English speaker is characteristically less assertive and uses more mitigation than the Spaniard. Indeed, although this behaviour is true in an informal context of rapport, the numbers clearly become inverted when we come to the asymmetrical formal context. Furthermore, it has been demonstrated that cultural differences regarding polite mitigation of disagreement are glaringly sensitive to changes of context and do not always reflect the expectations generated by specialised bibliography on the subject of stereotypical and rigid cultural patterns.

\section{REFERENCES}

Ballesteros M, F. J. (2001). "La cortesía española frente a la cortesía inglesa. Estudio pragmalingüístico de las exhortaciones impositivas". Estudios Ingleses de la Universidad Complutense, 9, pp.171-207.

Blum-Kulka, S. (1982). "Learning to say what you mean in a second language: a study of the speech act performance of learners of Hebrew as a second language". Applied Linguistics, 3, pp.29-59.

Bousfield, D. (2008). Impoliteness in Interaction. Amsterdam: John Benjamins.

Bravo, D. (2001). "Sobre la cortesía lingüística, estratégica y conversacional en español”. Oralia, 4, 299-314.

Bravo, D. (2003). "Actividades de cortesía, imagen social y contextos socioculturales: una introducción”. In D. Bravo (Ed.), Primer Coloquio del Programa EDICE. La perspectiva no etnocentrista de la cortesía: identidad sociocultural de las comunidades hispanohablantes (pp. 98-108). Stockholm: University of Stockholm.

Bravo, D. (2008): "The implications of studying politeness in Spanish-speaking contexts: a discussion" ("Las implicaciones del estudio de la cortesía en contextos del español. (Una discusión)". Pragmatics, 18, pp.577-603.

Briz, A. (2012). “La (no)atenuación y la (des)cortesía, lo lingüístico y lo social: ¿son pareja?” In J. Escamilla Morales and G. Henry Vega (Eds.), Miradas multidisciplinares a los fenómenos de cortesía y descortesía en el mundo hispánico (pp. 33-75). Barranquilla-Estocolmo, Universidad del Atlántico-Programa Edice.

Brown, P. \& Levinson, S. C. (1978). "Universals in language usage: politeness phenomena". In E. N. Goody (Ed.), Questions and Politeness: Strategies in Social Interaction (pp. 56-311). Cambridge: Cambridge University Press.

Brown, P. \& Levinson, S. C. (1987). Politeness. Some Universals in Language Use. Cambridge: Cambridge University Press.

Fernández-García, F. (2016a). "Hacia un análisis de la variación cultural, social y situacional en la percepción de la (des)cortesía". In A. M. Bañón Hernández, M. M. Espejo Muriel, B. Herrero Muñoz-Cobo and J. L. López Cruces (Eds.), Oralidad y análisis del discurso (pp. 223-238). Almería: Universidad de Almería.

Fernández-García, F. (2016b). "Bases teóricas para un estudio transcultural y variacionista de la (des)cortesía". Estudios de Lingüistica. Universidad de Alicante, 30, pp.79-100.

Fernández-García, F. (2020). "Estrategias de mitigación en la formulación del desacuerdo: estudio intercultural”. In M. González Sanz, C. Fuentes Rodríguez and E. Brenes Peña (Eds.), (Des)cortesía, actividades de imagen e identidad. (pp. 399-416). Sevilla: Editorial Universidad de Sevilla.

Fernández-García, F. (under evaluation). "Desacuerdo y descortesía en hablantes españoles e ingleses: un análisis de variación pragmática".

Fernández-García, F. \& Aguayo-Cruz, M. ${ }^{a}$ D. (2019). "Variación cultural y situacional en la gestión del desacuerdo". In Pragmalingüistica, 27, pp.10-31.

Fernández-García, F. \& Ortiz-Viso, T. (2018). "Tres dimensiones en el análisis de la variación de la (des)cortesía”. Revista de Investigación Lingüistica, 21, pp.133-158. 
Haverkate, H. (2003). "El análisis de la cortesía comunicativa: categorización pragmalingüística de la cultura española". In D. Bravo (Ed.), Primer Coloquio del Programa EDICE. La perspectiva no etnocentrista de la cortesía: identidad sociocultural de las comunidades hispanohablantes (pp. 60-70). Stockholm: University of Stockholm.

Hernández Flores, N. (1999). "Politeness Ideology in Spanish colloquial conversation; the case of advice”. Pragmatics, 9, pp.37-49.

Hernández Flores, N. (2003). "Cortesía y contextos socioculturales en la conversación de familiares y amigos". In D. Bravo (Ed.), Primer Coloquio del Programa EDICE. La perspectiva no etnocentrista de la cortesía: identidad sociocultural de las comunidades hispanohablantes (pp. 121-127). Stockholm: University of Stockholm.

Hernández López, M., and M. E. Placencia (2004). "Modos de conducir las relaciones interpersonales en interacciones de atención al público: el caso de las farmacias en Sevilla y Londres". Estudios de Lingüística. Universidad de Alicante, 18, pp.129-150.

Hickey, L. (2005). "Politeness in Spain: Thanks But No 'Thanks"”. In L. Hickey and M. Stewart (Eds.), Politeness in Europe (pp. 317-330). Clevedon: Multilingual Matters.

Holmes J. (2013). An Introduction to Sociolinguistics. (3rd ed.). Harlow: Pearson.

Holmes, J. (1995). Women, Men and Politeness. London: Longman.

Kotthoff, H. (1993). "Disagreement and concession in disputes: On the context sensitivity of preference structures”. Language in Society, 22, pp.193-216.

Lakoff, R. (1973). “The Logic of Politeness, or Minding your P's and Q's". Proceedings of the Ninth Regional Meeting of the Chicago Linguistic Society, pp. 345-356.

Leech, G. N. (1983). Principles of Pragmatics. London: Longman

Levinson, S. C. (1983). Pragmatics. Cambridge: Cambridge University Press.

Lorenzo-Dus, N. (2001). Compliment responses among British and Spanish university students. Journal of Pragmatics, 33, pp.107-127.

Schegloff, E. A. (2007). Sequence Organization in Interaction. Cambridge: Cambridge University Press.

Schiffrin, D. (1984). "Jewish argument as sociability". Language in Society, 13, pp.311-335.

Schneider, K. P. (2012). "Appropriate behaviour across varieties of English". Journal of Pragmatics, 44, pp.1022-1037.

Sifianou, M. (1992). Politeness Phenomena in England and Greece. A Cross-Cultural Perspective. Oxford: Clarendon Press.

Spencer-Oatey, H (Ed.) (2008). Culturally Speaking. Culture, Communication and Politeness Theory (2nd edition). London: Continuum.

Spencer-Oatey, H. (2002). "Managing rapport in talk: Using rapport sensitive incidents to explore the motivational concerns underlying the management of relations". Journal of Pragmatics, 34, pp. 529-545.

Spencer-Oatey, H. (2005). “(Im)Politeness, face and perceptions of rapport: unpackaging their bases and interrelationships". Journal of Politeness Research, 1, pp. 95-119.

Spencer-Oatey, H. (2007). "Theories of identity and the analysis of face". Journal of Pragmatics, 39, pp. 639-656.

Spencer-Oatey, H. (2008). "Face, (Im)Politeness and Rapport”. In H. Spencer-Oatey (Ed.), Culturally Speaking. Culture, Communication and Politeness Theory (pp. 11-47). London: Continuum.

Staley, L. (2018). Socioeconomic Pragmatic Variation. Amsterdam: John Benjamins.

Stewart, M. (2005). "Politeness in Britain: 'It's Only a Suggestion..."'. In L. Hickey y M. Stewart (Eds.), Politeness in Europe (pp. 116-128). Clevedon: Multilingual Matters.

Terkourafi, M. (2005). "Beyond the micro-level in politeness research". Journal of Politeness Research, 1, 237-262.

Wierzbicka, A. (2003). Cross-Cultural Pragmatics. The Semantics of Human Interaction. (2nd ed.). Berlin: Mouton de Gruyter. 
